\title{
Out of sight, out of mind: Family resemblances in lesbian donor conception
}

Petra Nordqvist, University of Manchester

Petra.Nordqvist@Manchester.ac.uk

Post peer-review version of article published in

Nordqvist, P. (2010) ''Out of sight, out of mind'. Family resemblances in lesbian donor conception', Sociology, 44(6): 1128-1144.

DOI: $10.1177 / 0038038510381616$

Please refer to the published version for citations.

This article draws on Petra's $\mathrm{PhD}$ research into lesbian couples' experiences of donor conception. For more information about other articles published by Petra about lesbian donor conception and assisted reproduction more broadly, please visit http://www.manchester.ac.uk/research/petra.nordqvist/

Petra's most recent project 'Relative Strangers' (2010-2013) (with Carol Smart) explored the impact of donor conception on family life among heterosexual and lesbian couples. The research explored parents as well as grandparents' experiences of donor conception in their families. The findings from this project are available in the book 'Relative Strangers: Family Life, Genes and Donor Conception'. If you are interested in reading more about the project and see our videos, please visit http://www.socialsciences.manchester.ac.uk/morgancentre/our-research/kinship-andrelatedness/relative-strangers/ 


\title{
Out of sight, out of mind: Family resemblances in lesbian donor conception
}

\author{
Petra Nordqvist \\ University of Manchester \\ Petra.Nordqvist@Manchester.ac.uk
}

\begin{abstract}
Family resemblances and connectedness constitute a recent interest in sociological debate. This paper seeks to build on, and expand, this debate by empirically exploring the meaning of physical family resemblances in the context of lesbian donor conception. This constitutes a neglected area as previous studies primarily explore gamete donation and physical resemblances in the context of heterosexual assisted conception. Considerably less attention has been paid to the specific dynamics inherent to lesbian donor conception. The paper draws on a qualitative study of 25 lesbian couples in England and Wales with experiences of pursuing both self-arranged and clinical donor conception in the context of a lesbian couple relationship. Building on work in the area of kin, connectedness and family resemblance, this paper argues that seeking resemblances can be as much about creating distance as connectedness in the context of lesbian couple donor conception.
\end{abstract}

Keywords

Connectedness, donor conception, donor 'matching', family legitimacy, family resemblances, lesbian, genotypes/phenotypes 


\section{Introduction}

Until relatively recently, matters of kinship have received little sustained attention within sociological studies of intimate and family life. The overarching debates around the changing patterns of family life in recent decades have been strongly influenced by the suggested increase of individualisation, and few studies have explored aspects of kinship and connectedness (but see Finch and Mason 1993, 2000). However, sociologists have now begun to take an interest in concepts and negotiations of relatedness. This is illustrated in two recent publications. First, Mason (2008) argues that there is a contemporary popular fascination with kinship; she seeks to outline a conceptual framework to explain why kinship fascinates. Second, Smart (2007) suggests that relatedness is central to contemporary family and personal life, and introduces a theoretical framework which centres on connectedness, not individualism.

Building on this recent work, and extending it, I explore notions of connectedness, kinship and family resemblances with a particular focus on physical family resemblances within the context of lesbian donor conception. I shall do so initially by exploring the UK context of lesbian reproduction, I then outline the relationship between physical resemblance and family connectedness, and I also outline the methodology of the study. Thereafter, I shall draw on my own research data to explore how family resemblances are perceived by lesbian couples, and how couples negotiate the involvement of a sperm donor. I shall argue that the issue of resemblances works in quite complex ways within lesbian families and that seeking resemblances can be as much about creating distance as about connectedness (hence my title). I shall also argue that lesbian couples utilise a conventional discourse of family resemblances as a normalising strategy.

Matters of kinship, and family resemblance, come to the fore in the context of donor conception. A growing body of anthropological work on new reproductive technologies indicates that medical developments in infertility treatment, as well as the use of donated gametes, raise new issues, concerns and negotiations relating to notions of kinship and relatedness (Franklin and McKinnon 2001, Strathern 1992). One of the areas in which assisted conception raises particular concerns for the families involved is around physical resemblances. It is established clinical practice that staff seek to 'match' the physical characteristics of the donor with those of the birth-mother or the non-genetic father in a heterosexual couple. The Human 
Fertilisation and Embryology Authority (from now on 'HFEA'), which regulates licensed donor conception in the UK, states in its code of practice $\left(6^{\text {th }}\right.$ Edition, 2004) that:

...those seeking treatment are expected not to be treated with gametes provided by a donor of different physical characteristics unless there are compelling reasons for doing so. (HFEA, 2004: para 3.19)

Empirical research suggests that this practice is also commonly supported by women and heterosexual couples themselves. It has been understood to allow for heterosexual couples to pass as a child's biogenetic parents, and to fit in with an ideological notion of 'the family' (Haimes 1992).

In contrast to heterosexual couples who access licensed donor sperm, lesbian couples diverge from heterosexual family ideals. Unlike heterosexual couples, a lesbian couple does not 'pass' as a hegemonic 'family', or as a parental unit which is able to reproduce biogenetically. It might appear then, that donor 'matching' ceases to carry meaning in this context. However, my interviews with lesbian couples indicate that physical appearance and matching significantly shape their donor conception processes. While the meaning of donor selection in heterosexual donor conception has been explored, considerably less attention has been paid to the meaning of physical resemblance in lesbians' donor conception practices. With the exception of Jones (2005), it remains largely unclear how physical family resemblances are constructed, perceived and experienced in such a context in the UK. Situated in the context of British research into lesbian reproduction and parenthood (Almack 2008, Dunne 1997, Donovan 2008), and adding to this, my paper focuses on exploring the narratives of the lesbian couples in my study who desired to 'match' physical family resemblances through their donor, and how this desire shaped their conception practices. The paper thus focuses specifically on the accounts of lesbian couples who sought to 'match' donors (who were in majority in my sample). It is not within the remit of this paper to discuss the way in which family resemblances were constructed after birth, or the construction of family resemblances in the everyday life of lesbian parent families. 


\section{The UK context of lesbian reproductive practices}

Same sex couples' access to reproduction and a family life is increasingly protected in English and Welsh law through recent legal changes, primarily the Adoption and Children Act 2002, the Civil Partnership Act 2004, and also the Human Fertilisation and Embryology Act 2008.

Today there are two primary routes through which lesbians become parents using donor sperm: self-arranged conception and clinical conception. Self-arranged conception refers to donor insemination that takes place outside reproductive health clinics, in which couples privately arrange sperm donations with a man. In clinical conception couples access donor sperm through NHS or private health clinics. Selfarranged conception has long been a common feature of lesbian conception practices in the UK (Haimes and Weiner 2000), which is likely to be linked, in part, to the legal restrictions that have, until recently, denied lesbians access to UK infertility clinics. However, an increasing number of lesbian couples are now, seeking fertility treatment in health clinics licensed and regulated by the HFEA (Human Fertilisation and Embryology Authority 2006).

These two different routes are differently regulated and recognised in UK law and have different outcomes for the legal status of the parties involved. Couples who participated in this study pursued conception between the mid 1990s and 2008 (before the revisions of the Human Fertilisation and Embryology Act 2008 ('the 2008 Act') came into law), and were thus subject to regulation under the Human Fertilisation and Embryology Act 1990 ('the 1990 Act'). The key issues under consideration for these couples were how the law recognised the non-birth mother, as well as how it legally positioned the sperm donor. The birth mother was automatically recognised as the legal mother of the child in both routes. In cases where lesbian couples accessed licensed donor conception, the donor was excluded from all parental rights, he was not named on the birth certificate and the child did not have a legal father. The 1990 Act implicitly excluded lesbian couples from accessing licensed treatment, and did not recognise any parental status of the non-birth mother. For her to acquire parental status, the lesbian couple had to take legal steps, made possible by the Adoption and Children Act 2002.

The law worked quite differently for couples who pursued self-arranged conception. In such cases, the donor was the legal father of the child (Stonewall 2008). If he was named on the birth certificate he had automatic parental 
responsibility of the child. In cases where he was not named, he could pursue this legal recognition. This could threaten the non-birth mother's chances of adopting the child, or becoming legally recognised as its parent. ${ }^{1}$

\section{Cultural and social meanings of family resemblances}

Strathern (1992) argues that Euro-American kinship discourse consists of a traffic of two sets of ideas: connectedness by blood/biogenetics (nature) and connectedness by marriage (society). Investigating the discourse of biogenetic kinship more closely, Carsten (2001) demonstrates that it centres on an understanding that biogenetic substance is transferred from parents to child, and that this transference is culturally understood to constitute bonds of relatedness. In cultural contexts such as the British, which emphasise such transference, the 'gene' is a particularly powerful symbol: it is seen to carry a cultural meaning of predictability and permanence, and it is constructed as a stable and meaningful entity (Nelkin 2006: 171). This discursive construction of genetic relatedness is socially powerful as it re-establishes the powerful category of 'nature' (Franklin et al. 2000: 10).

Biogenetic kinship is perceived as equally inherited from 'both sides' of the family. Socially, this is seen as visible in physical characteristics (Richards 2006), making physical resemblance an important feature of Euro-American kinship discourse. Mason (2008: 33f.) indicates that physical resemblance is perceived as a tangible fact of kinship as it is understood as hinting of non-elective, undeniable and evidential kinship bonds. This idea relates to, and interlinks with, a cultural understanding that the relationship between relatives is seen to lie in the recognition of the body in the other (Marre and Bestard 2009: 69). When a baby is born, its body is seen to constitute a tie of social identity between it and the family; it is understood to become part of the family body and ties of social relations are perceived to exist. Family resemblances are understood to signal a continuity of family relations and identity.

Family resemblances also have a meaning in the social identification of family relationships. Becker et al. (2005) argue that 'talk' about family resemblances affirm family connections. They demonstrate that such talk supports a hierarchy of family legitimacy (2005: 1301). Clear physical resemblance confirms family connectedness, and socially such families are established as legitimate families. Where there is a lack of physical resemblance, family legitimacy is, however, questioned, and such families can be exposed to social stigma. Families created using donor conception are amongst 
those which are particularly vulnerable to the stigma associated with failing to adhere to this discourse.

These studies indicate that 'family' is not only constructed in the family unit, but it is also constructed and confirmed, or challenged, in everyday life. This ties in with recent developments in the study of the changing patters of family life. Morgan (1996) suggests that family can no longer be recognised as a social structure or an entity to which individuals unambiguously belong, but rather as a set of practices. Extending Morgan's work on family practices, Finch (2007) argues that families are not only constituted by what they do together, but must also be displayed, and recognised by others, to be confirmed as family units. Finch argues that families therefore must undertake what she calls 'display work', noting that 'the meaning of one's actions has to be both conveyed to and understood by relevant others if those actions are to be effective as constituting "family" practices' (Finch 2007: 66). ${ }^{2}$ This article utilises the concept of 'display work', and the notion that family practices are not only 'done' but also displayed socially to others.

\section{The study}

The study is based on qualitative in-depth interviews with 25 lesbian couples in England and Wales with experience of jointly pursuing parenthood using donor conception.

As noted in previous studies of non-heterosexual life experience, same-sex couples constitute a 'hidden' population and a hard-to-reach group: no sampling frame exists for their recruitment (Dunne 1997). Therefore, studying a sample consisting of such couples raises particular challenges in terms of recruitment. As random sampling is not an option, a purposive sampling based on self-selection was employed in the study. Lesbian couples were recruited using self-selection through online and offline gateways. Online recruitment primarily took place using 'message boards' for gay and lesbian parents ${ }^{3}$. Both the sample size and the method of recruitment meant that the couples in this study are unlikely to be a representative cross-section of the population of UK lesbian couples. Themes that emerged from the interviews, however, are likely to have generalisability beyond the sample from which they were drawn as the data offer in-depth understandings suggestive of the ways in which these processes are experienced by other couples (Mason 1996: 93). 
The couples participated in interviews which were loosely structured around four overarching themes: planning conception; doing inseminations; connectedness, family and kin; and the couple relationship. To gain an insight into the experience of the couple, and to generate rich data, I conducted couple interviews where possible (Nordqvist 2009). A total of 45 women took part (I conducted five individual interviews in cases where couple interviews were too impractical). All interviews were recorded and transcribed verbatim.

Fieldwork was conducted between September 2007 and March 2008. It is possible that the changes to the 2008 Act will impact on lesbian couples' future routes to conception. Nevertheless, this study demonstrates enactments of donor conception, as well as desires and perceptions of family life, which are likely to remain valid after the 2008 Act comes into force.

The sample was composed of couples who pursued licensed donor conception (52 percent) and those who self-arranged conception (48 percent). ${ }^{4}$ Participants were between 23 and 56 years of age. 36 percent had left school at 18, whilst 64 percent had a higher education qualification. Using highest level of education as a measure of social class (Graham 2007), this indicates that women of both working and middle class backgrounds were represented within the sample. 42 women identified as white British, Welsh or English and three women identified as of either mixed ethnic origin, Chinese British or Black British. Names, places and identifying details in the interview extracts have been altered to protect participants' anonymity.

\section{Choosing donors}

The interviews indicate that lesbian couples carefully considered the physical characteristics of the donor in their process of donor selection. I have already noted that it is established practice that women and heterosexual couples who conceive using licensed donor sperm 'match' the physical characteristics of the donor with those of the birth mother or the non-genetic parent in the couple. My findings suggest that lesbian couples who accessed licensed donor sperm acted no differently in this regard. Commonly, couples who went to clinics mobilised a discourse of 'matching' in their accounts of their donor selection process. For example, Kim and Caroline state respectively:

[W]e were trying to go for people whose physical characteristics were a bit similar to Nicola's. (Kim, expecting baby together with Nicola) 
They give you a sheet, which says hair colour, eye colour, and you put your preference down. [...] So, we were presented with this sheet and thought, well, how are we going to do this? Well, let's match it with Gillian. (Caroline, birth-mother of her and Gillian's two children)

It should be noted that couples who conceived in clinics choose donors in dialogue with clinical staff. According to the respondents in the sample, clinical staff commonly advised them to use donors with 'matching' physical characteristics.

This desire to find a 'matching' donor was not restricted to the clinic population in my sample. Couples who pursued self-arranged conception also considered it important to find a donor of appropriate physical characteristics; identified as 'matching' ones. Hanna's account represents a common response in this group:

Ideally we wanted him to look like us. (Hannah, 23, non-birth mother) Although the choice of donor in the context of self-arranged conception is not mediated by HFEA guidelines, the couples expressed a desire for 'matching'. The fact that most of the self-arranging couples did this, highlights how powerful the discourse of family resemblances is in shaping these conception narratives. The couples who self-arranged had to consider a number of factors when selecting donors, for example, level of parental involvement, trustworthiness, risk of contracting infections, and location. The risks involved were exacerbated by the regulations which recognised the donor as the legal father of the child. Finding a donor who ticked all boxes was not easy. Nevertheless, couples in this category often sought 'matching' donors. In some cases the importance of physical characteristics was downplayed, but still shaped their choice. This is illustrated in Lisa's account:

Both [my partner] and I are blonde, blue-eyed, fair-skinned and as it happens so is our donor. And that was by chance. Some of the other people we had talked to have dark hair, brown eyes or something and that we didn't mean we ruled them out, but the fact that [our current donor] actually had similar physical characteristics to both of us was a tick in his favour, because actually then the child might look a bit like both of us. (Lisa, 29 mother of one together with partner)

An overarching desire to 'match' the child's physical characteristics with those of the couple emerged across both groups. Building on Marre and Bestard (2009), ideas of 
'matching' and physical resemblances are intimately interconnected with conventional family and kinship discourses as they rehearse heteronormative ideas of family recognition. A biogenetic, heteronormative family ideal was thus highly influential of how conception and family was imagined among these couples. The assertions around family resemblances and 'matching' signal an engagement with conception according to such conventional family models.

It should be noted that there were some voices critical of these practices, but they were in minority as only two couples felt that 'matching' was problematic. It should also be noted that 'matching' practices were not as prevalent among the few couples (4 of 25) in the study who wanted the donor to be involved as a dad, and who chose a donor based on a social relationship. In these cases a slightly different set of issues around likeness were more prevalent. However, most couples did not want an involved donor, and they experienced physical resemblances as an important issue to negotiate. This paper focuses on these experiences.

\section{Donor matching and biogenetic parenthood}

The mobilisation of a 'matching' discourse ties in with an idea that physical similarity interrelates with biogenetic bonds of relatedness (Richards 2006). Shelly and Rosie pursued clinical conception with Shelly as birth-mother. Shelly states:

I think it would be nice [if the donor matches Rosie], I mean people like to see themselves in their children. Obviously that wouldn't necessarily at all going to be genetically true with Rosie but going to be sort of similarities. (Shelly, 30, expecting baby together with Rosie, 25)

Shelly states that the reason for seeking a 'matching' donor was that while the baby was not going to be Rosie's baby genetically, it would almost be so if there were to be physical similarities. The couple aspired to create what can be understood as phenotypical resemblance between Rosie, the non-birth mother, and the child. Another variation of this can be found in my interview with Harriet and Julie who pursued self-arranged conception using a donor found on the Internet with Harriet as the non-birth mother. They state:

Harriet When we first went on the Internet we had quite a few people and I looked at the pictures and I have to say I did choose ones that were more similar looking. I wanted ones that looked more like Julie so that 
they' $d$ have brown eyes and light brown hair so that the baby might resemble her.

Julie 'Cause naturally it's going to. [Laughing]

Harriet Yeah, I know but that was just my way of you being in sort of... I know it's not going to look like you but it was just my way of having you in it a little bit. (Harriet, 36 and Julie, 30)

Although both of these accounts indicate couples' awareness of the biogenetic nonconnectedness between the non-birth mother and the child, they also highlight how such connectedness is being negotiated through their choice of donors. Couples who desire a donor of 'matching' characteristics can be understood to draw on a discourse of kinship and relatedness as genetic material being transferred from parent to child (Carsten 2001). Quiroga (2007: 145) notes that shared genes (a shared genotype) between parents and child are substituted for a shared phenotype (looking alike) in the context of donor conception. Drawing on Rabinow's (1996: 99) analysis of 'biosociality' in which nature can be seen as modelled on culture, biology is inscribed into an idea based in the social world that 'looking alike' indicates a biogenetic bond of relatedness. 'Biology' in this context can be seen to be defined through the 'social' - a biological relationship is established if it is socially recognised as such - with the movement between the two categories mediated through phenotypes. By deploying a discourse about genotypes as phenotypes, lesbian couples can be seen to socially construct a genetic relationship between both women and the child, constructing the child as if it was theirs biologically. These assertions of biogenetic connections and twosome parenthood build on and strengthen conventional biogenetic nuclear family discourse which, problematically, render invisible ethics of care, social parental ties, single or multiple parental constellations and, also, non-heterosexual parenthood.

This biogenetic construction can only be achieved through the eradication of the donor. Knowledge that a donor has genetically contributed to the child is obscured and as he moves out of sight physically, his genetic involvement is also moved out of mind: the child can then be biogenetically attached to the lesbian couple. Thus, what can be traced are notions of resemblance as connectedness, but also distance. 


\section{Physical resemblance and family connectedness}

My interviews suggest that this negotiation of physical resemblances and biogenetic connectedness in the lesbian mother family has implications for the identification of relatedness. Lisa and her partner sought to conceive over a period of many years. Both partners were keen to give birth to their children, and over the years of trying, both women acted as birth mothers at various times. Eventually Lisa was the one to become pregnant. Although Lisa gave birth, she highlights that the child looks similar to her partner, and says:

[W] hen I look at photographs of us together, our child looks more like [partner] than she does like me. Actually [she] has been out with our baby and people have commented and said, "Oh, don't you look like your mum", obviously assuming that she is the biological mum. I think that's great! When we do go out, if we're carrying the baby in a sling or anything, generally I want my partner to be carrying her, because I like that assumption to be in place. [...] I really like it whenever anything happens that really affirms my partner's place as the parent. (Lisa, 29)

Lisa's account illustrates that physical resemblance can be a strategic way to confirm and convey family relationships. The confirmation lies in people's comments on the physical likeness between the baby and the non-birth mother, referring to a supposed biological relationship that is implicit in such an assumption. A family relationship that between parent and child - is thought to follow from such a biogenetic relationship. Lisa's account suggests that she strategically uses such a discourse to construct and affirm the connectedness between her partner, the non-birth mother, and the child (compare Becker et al. 2005). Drawing on Finch (2007) the lesbian family not only undertakes family practices, but their accounts also signal that the display of family is important for them to be constructed as such. Lisa utilises normative family discourse instrumentally to create family connections.

The flip side of this discourse is a notion of physical difference as a sign of family disconnectedness. Fiona experienced that of a lack of physical resemblance between herself and her child meant that the parent-child bond was socially questioned:

You see, it's always been a huge thing for me, because I'm so dark. [...] I have dark hair. My child is very fair skinned, very blond and has blue eyes. So, even when he was three and sitting on my lap and calling me mummy 
people would still do a double-take and try and figure out. (Fiona, 41, single mother of four)

Fiona felt that, because she and her son looked different from each other, the parentchild relationship was called into question. Likewise, for Amy, who is a non-birth mother, the anticipated likeness in looks between her child, its birth mother Rachel and Rachel's family was a source of worry before the child was born. Amy states:

Amy I was really worried about the genetics thing.

Interviewer What where you thinking about?

Amy Well not really genetics just more that everybody would say "Oh she looks just like you Rachel" and "Oh she is just like you" [...]. Because it makes her family feel that they are closer. (Amy, 28, non-birth mother together with Rachel, 33)

The power of looks to affirm family bonds is confirmed in Fiona's and Amy's accounts of physical difference as a source of worry (see also Becker et al. 2005). Amy's account suggests that the relationship of the birth mother (Rachel) to her family of origin is carried forward through the physical resemblance between Rachel and the child, and potentially questioning Amy's own relationship to the child. Thus, family resemblances also link in with ideas of exclusion, disconnectedness and distance.

I argue that lesbian couples' strategic use of physical resemblance, and the worries it can incur, relate to the Euro-American kinship discourse of what it means to reproduce, and what the inherent meanings of such reproduction is thought to be. Strathern notes that 'as biology is understood by the lay person, reproduction appears as the process by which an original plant or animal produces individuals similar to itself.' (Strathern 1995: 354). Lesbian couples can be understood to mobilise a discourse of reproduction as the production of something similar. This understanding of reproduction has particular implications for family relationships. Strathern states:

Euro-American understandings of the similarities involved in human reproduction are, of course, not at all neutral as to the nature of the relationship at issue. A relationship is thought to inhere in a continuity of (personal) identity. (Strathern 1995: 354, my emphasis) 
Strathern indicates that the reproduction of something that is similar is also the production of a continued identity, constructing a relationship between the reproducer and the reproduced (see also Marre and Bestard 2009). Physical resemblance is central to this: it 'constitutes the relational identity of kinship' (Marre and Bestard 2009: 70). The interviewees quoted (above) understand physical resemblance as something that signifies, and implicates, family relationships. Drawing on Marre and Bestard (2009: 69), such a discourse has particular implications for the recognition of family, suggesting that physical resemblance hints at family identity: physical resemblance carries forward family relations (see, for example, Amy's account above).

Physical resemblance thus has implications for the construction of family and for the 'display' of family relationships and connectedness. Lesbian couples' aspirations to have 'matching' donors relate to the ambition to identify the child as part of the family and place the child in the family unit of the couple. Although the racialisation of family resemblances is not the main focus of this article (it will be explored elsewhere), it should be noted that these practices are also influenced by constructions of race (Quiroga 2007). Linda and her partner Annette wanted a donor with blue eyes, but as there was a shortage of donor sperm, they ended up using another donor who they did not want:

[T]he last couple of times we kept getting off with this donor, we call him the short Italian bloke $[\ldots][\mathrm{H}] \mathrm{e}$ was dark-skinned, dark hair, dark eyes which was completely not what we wanted. We really wanted a child with blue eyes. I know it sounds silly but because I've got blue eyes and Annette has green eyes, it looks more natural that $[\mathrm{a}]$ child who's ours, $[\ldots]$ dark eyes just wouldn't... it would be then very obvious that the child wasn't ours. (Linda, 39, mother of one together with Annette, 33)

In Linda's account, the choice of a 'matching' donor, and the rejection of another, highlights an aspiration to tie the child to the lesbian couple. Following Marre and Bestard (2009: 76) the identity of the baby as part of a family is established through the resemblances between bodies. Lisa's account further highlights this, pointing to the concern to connect the child to the family unit of the lesbian mothers. Lisa states:

Literally when he was first born, one of the first times I held him, I looked at him and I was trying to identify which features come from me and which 
come from the donor. [...] I'd prefer him to look like me than to look like the donor, because at least then he's part of our family unit. (Lisa, 29)

A shared phenotype is understood to confirm the family bonds between the lesbian couple and their child, and physical resemblance confirms the child's place in the family group (Becker et al 2005: 1306).

This identification of the baby with the lesbian family is also the dis-identification and disconnection of the child from the donor. If the donor and the mother look alike, it is assumed that the child will have a physical resemblance to both. The child still looks like donor, but also like the mothers. If the child resembles the donor, and not the mothers, then there is a threat that the child is perceived as related to him, and thus a suggestion that the child belongs to a different family than the one created by the lesbian couple. As Mason (2008) notes, such resemblance would signal a fixed, nonelective bond between the child and the donor, thus calling into question the bonds between the lesbian couple and the child. When the donor moves out of sight, i.e. when the baby physically resembles the mothers, this threat is contained. The construction of relatedness using the particular resource of physical resemblance depends on the careful exclusion of the donor as a potential relative.

Through these practices, lesbian families thus link their family form to conventional family models. Their engagement with such ideals can be understood as instrumental and strategic: they self-consciously use and utilise a discourse which links family relationships with physical resemblances. It is important to remember that lesbian couples are not unique in this practice or in their desire to construct such as family, but that it is institutionalised and established practice to 'match' couples and donors in the UK, and this is widespread practice among heterosexual couples (Haimes 1992).

While these practices may to some extent be creative, they are undertaken in the pursuit of something very normative. They facilitate the construction of a biogenetically connected two-parent family, that which is socially and culturally perceived as a 'normal' family. Such normativity marginalises families that diverge from this. Thus, a contradiction is embedded in this, as 'matching' practices build on a discourse which in itself excludes non-heterosexual parenthood, non-genetic parenthood and gives no recognition to the social nature of parenthood, relationships and connectedness. It may therefore seem surprising that lesbian couples draw on 
notions of parenthood that can only ever give partial recognition to their family model. I now move on to explore this issue further.

\section{'Matching' and family legitimacy}

In the process of seeking donors for self-arranged conception, Lisa and her partner chose a white donor, and consciously rejected an Asian donor that showed interest in donating. Lisa states:

I do think we were right in our choice of at least having a white donor, because I think even if [the baby] happened to have different coloured hair, as it is her eye colour is different to both mine and [partner's], it's kind of blue, but a different shade. It's more similar to [partner's] than it is to mine, but her eye colour comes from the donor. But that's irrelevant. People don't notice that. [...] I think that that does make a difference. It does help. It makes it easier, anyway. People don't question it. (Lisa, 29, mother of one together with partner)

What 'people do not notice' is that a donor was involved in making the child. The logic of Lisa's account is that when the donor is out of sight, he is also out of mind. Matching can therefore be as much about making connections as it is about distance and disconnections. This is illustrated in Rachel's account, which highlights how couples can aspire to implement disconnectedness:

[W]e did want that [the donor] didn't have too many you know like massive hook nose or you know some like a big feature that was going to be passed on [so] that every time you looked on the child you would always see something that would identify [with the donor]. (Rachel, 33, mother of one together with Amy, 28)

It follows, that when the donor can be traced in the physical characteristics of the child, he is also recognised as present in the child, and serves as a reminder of his involvement in making him/her. Lisa's and Rachel's comments signal that the practice of 'matching' is the practice of moving the donor and the donor conception out of mind both for the women themselves and also for an imagined 'viewer' of the family unit.

Lisa's account above indicates why this containment of the donor's involvement is important. She states that because she, her partner and their child look similar 'people 
don't question it'. This understanding was echoed in my interview with Hannah who together with Anne conceived a son using self-arranged conception:

Hannah I think at first it was one thing [we wanted] a donor that had the same looks as either Anne or myself, or Anne more so than me. Not to the extent, we need someone who's 6 foot 4 and really good looking, tall, dark and handsome, but certainly that the baby was going to look as if it was ours. I don't know, rather than being totally different.

Interviewer Yes, did that feel important?

Hanna Yes, I think only to the extent that you get less questions asked or we thought you'd get less questions asked[.] (Hannah, 23, mother of one together with Anne, 34)

Becker et al. (2005: 1301) suggest that the discourse of resemblance supports a hierarchy of family legitimacy. Clear physical resemblance confirms family belonging as it is culturally seen to indicate blood relationality. However, unclear physical resemblance raises questions and is socially stigmatised. Lisa and Hannah's accounts indicate that they fear that physical difference would mean that their families would be socially questioned as it would physically signal the involvement of a donor. The utilisation of family resemblances and the strategically undertaken 'matching' processes is thus a strategy to normalise the lesbian mother family.

This contextualises lesbian mothers' enactment of donor conception, and the problematic utilisation of normative ideas of two-some parenthood and likeness. The donor, and the use of his gametes, represents a constant threat to these families. It is a threat in that lesbian couples' conception is culturally understood as an impossibility ${ }^{5}$. The donor, who represents both a concept and a role, but is also an individual, has the power to challenge the family bonds between the lesbian mothers and the baby, and the baby's place in the lesbian mother family: socially and culturally, but also legally. Lesbian couples can be understood to use matching in an instrumental way to normalise their family, and to counteract discrimination feared and felt in their everyday life. They utilise normativity to safeguard against the threat that the donor represents, and to legitimise their family form. Thus, underlying these practices is an everyday radicalism, and the fact that their normality is always only partial as ultimately, they are same-sex couples. 


\section{Conclusion}

The participants in this study undertook unconventional conception practices in lesbian relationship contexts; they were socially and culturally recognised to transgress a traditional family model. It would appear that they could not hope to 'pass' as a conventional heterosexual nuclear family by 'matching' the donor's looks with those of their own. In principal, at least, it seemed that the construction of physical family resemblances through donor selection would cease to carry meaning. Intriguingly, my findings suggest otherwise.

In conclusion, the interviews indicate that lesbians engage in donor selecting practices by mobilising a discourse that their family is connected through biogenetic links. By constructing themselves as the 'natural' parents of the child, lesbian couples seek to access the cultural and social power that lies in a discourse of the 'natural' family (Franklin et al. 2000). Following Mason's (2008) theorisation of physical resemblances as culturally understood to signal non-elective undeniable forms of kinship, which ties in with Nelkin's suggestion that physical resemblances signal genetic connections (representing permanence and predictability), this suggests that lesbian couples' engage with biogenetic connectedness as an aspiration to display the bonds of relatedness between the lesbian mothers and the child as those of the nonelective, fixed and stable type. It hints at a desire to construct their family links as undeniably 'there'. This can be seen as a way to counteract the cultural perception that social kinship bonds, which are the basis for lesbian couple reproduction and an integral part of lesbian couples' parenthood, are 'weaker' than biogenetic ones. The construction of physical family resemblances represents a route for these couples to negotiate prevalent heteronormative assumptions about families, and to try to minimalise the homophobic consequences this has for them, their families and their children. This is a way in which 'matching' carries specific meaning in the context of lesbian donor conception, as opposed to heterosexual donor conception, and which gives Finch's (2007) understanding of 'display work' a whole new, very literal, meaning: it highlights the normative importance of looks and physical resemblance for the recognition and legitimisation of (marginalised) family relationships.

This specific way of constructing kinship bonds can only take place through the symbolic eradication of the sperm donor, a theme that emerges in multilayered ways throughout my interviews. The logic that runs through the various practices is that when the donor is out of sight in the physical body of the child, he is also out of mind 
in the imagined 'other', as well as in the mind of the mothers. This means that he 'disappears' in a number of ways: as a person; as someone to whom the child is related; as a potential parent; and as a potential threat to the lesbian family unit. The picture that is constructed, and the family that lesbian couples aspire to display, is one in which the child unambiguously belongs to the lesbian mother family unit. This shows that seeking family resemblances is just as much about connectedness as it is about disconnectedness; the two being intrinsically linked.

By hiding the involvement of a donor and the methods of conception, and appealing to identifying family connectedness through family resemblances in normative ways, these practices reproduce the social invisibility of non-genetic parent-child connections and donor conception in general. As already noted, very few lesbians who participated in this study were critical of this practice. One of them was Fiona who says:

I think it's a bit weird really when people [...] try and find a donor who has certain looks to minimise the difference in looks between themselves and their partner. It's almost as though you're not being entirely honest about the fact that there isn't a genetic relationship there. Almost as though you're trying to disguise it or put some sort of aesthetic band aid on it so that it's not so obvious. And I think there is nothing wrong with not being genetically related to your child. When you do that you're implying that there is or that you want to make it harder for the world to be able to tell. (Fiona, 40, mother of four)

In and of themselves, the practices of 'matching' serve to conceal a foundational and inevitable condition of lesbian couple parenthood: non-genetic family relationships and donor conception. Many of the lesbian couples try to fit in with a notion of family which arguably fundamentally discriminates against them, their family form, and their way of becoming parents. Although a discourse of family resemblances may offer a momentary relief to them and their children from marginalisation associated with difference, and I do not wish to underestimate the importance of this, it does not challenge built-in assumptions privileging biogenetic connectedness and the heterosexual nuclear family ideal. 


\section{References}

Almack, K. (2008) 'Display work: Lesbian parent couples and their families of origin negotiating new kin relationships', Sociology, 42(6):1183-1199

BBC News (2009) 'Lesbians given equal birth rights', 31 August. Available at <http://news.bbc.co.uk/go/pr/fr/-/1/hi/uk/8225158.stm> (Accessed on 1 September 2009)

Becker, G. et al. (2005) 'Resemblance talk: A challenge for parents whose children were conceived with donor gametes in the US', Social Science and Medicine, 61:1300-1309

Calhoun, C. (2000) Feminism, the Family and the Politics of the Closet: Lesbian and Gay Displacement. Oxford: Oxford University Press.

Carsten, J. (2001) 'Substantivism, antisubstantivism and anti-antisubstantivism', pp. 29-53 in S. Franklin and S. McKinnon (eds) Relative Values. Reconfiguring Kinship Studies. Durham: Duke University Press.

Dolgin, J. (1997) Defining the Family. Law, Technology and Reproduction in an Uneasy Age. New York: New York University Press.

Donovan, C. (2008) 'It's not really seen as an issue, you know, lesbian infertility it's kind of "what's that?"': Lesbians' unsuccessful experiences of medicalised donor insemination', Medical Sociology Online, 3(1):15-24. Available at <http://www.medicalsociologyonline.org/> (Accessed 26 January 2009)

Dunne, G. (1997) Lesbian Lifestyle: Women's Work and the Politics of Sexuality. Basingstoke: Macmillan Publisher.

Finch, J. (2007) 'Displaying families', Sociology, 41(1):65-81

Finch, J. and Mason, J. (1993) Negotiating Family Responsibilities. London: Tavistock/Routledge.

Finch, J. and Mason, J. (2000) Passing on: Kinship and Inheritance in England. London: Routledge.

Finkler, K. (2000) Experiencing the New Genetics. Family and Kinship on the Medical Frontier. Philadelphia: University of Pennsylvania Press.

Franklin, S. and McKinnon, S. (2001) 'Introduction. Relative values: Reconfiguring kinship studies', pp. 1-25 in S. Franklin and S. McKinnon (eds) Relative Values. Reconfiguring Kinship Studies. Durham: Duke University Press. 
Franklin, S. et al. (2000) 'Introduction', pp. 1-16 in S. Franklin et al. Global Nature, Global Culture. London: Sage.

Gabb, J. (2005) 'Lesbian m/otherhood: Strategies of familial-linguistic management in lesbian parent families', Sociology, 39(4):585-603

Graham, H. (2007) Unequal Lives: Health and Socio-Economic Inequalities. Maidenhead: Open University Press.

Haimes, E. (1992) 'Gamete donation and the social management of genetic origins', pp. 119-147 in M. Stacey (ed) Changing Human Reproduction. Social Science Perspectives. London: Sage.

Haimes, E. and Weiner, K. (2000) “'Everybody’s got a dad...”. Issues for lesbian families in the management of donor insemination', Sociology of Health and Illness, 22(4):477-499

Human Fertilisation and Embryology Authority (2004) 'Code of Practice'. 6th edition. Available at <http://hfea.gov.uk> (Accessed 2 September 2009)

Human Fertilisation and Embryology Authority (2006) 'Figures for treatment of single women and lesbian couples 2000-2005'. Available at <http://www.hfea.gov.uk/cps/rde/xchg/hfea> (Accessed 31 October 2006)

Jones, C. (2005) 'Looking like a family: Negotiating bio-genetic continuity in British lesbian families using licensed donor insemination', Sexulities, 8(2):221-237

Marre, D. and Bestard, J. (2009) 'The family body: Persons, bodies and resemblance', pp. 64-78 in J. Edwards and C. Salazar (eds) European Kinship in the Age of Biotechnology. Fertility, Reproduction and Sexuality series. Oxford: Berghahn Books.

Mason, J. (1996) Qualitative Researching. London: Sage Publications.

Miles, M. and Huberman, A. (1994) Qualitative Data Analysis. An Expanded Sourcebook. $2^{\text {nd }}$ ed. London: Sage Publications.

Morgan, D. (1996) Family Connections. An Introduction to Family Studies. Cambridge: Polity Press.

Nelkin, D. (2006) 'Gene as a cultural icon’, pp. 171-176 in A. Clarke and F. Ticehurst (ed) Living With the Genome. Houndmills: Palgrave Macmillan.

Nordqvist, P. (2009) Conceiving Together. Lesbian Couples' Pursuit of Donor Conception. Unpublished PhD Thesis, University of York.

Oxford Paperback Dictionary (1994) Fourth edition. Oxford: Oxford University Press. 
Quiroga, S. (2007) 'Blood is thicker than water: Policing donor insemination and the reproduction of whiteness', Hypatia, 22(2);143-161

Rabinow, P. (1996) Essays on the Anthropology of Reason. Princeton: Princeton University Press.

Richards, M. (2006) 'Heredity: lay understanding', pp. 177-182 in A. Clarke and F. Ticehurst (ed) Living With the Genome. Houndmills: Palgrave Macmillan.

Rights of Women (1984) Lesbian Mothers on Trial. A Report On Lesbian Mothers and Child Custody. London: Rights of Women.

Smart, C. (2007) Personal Life: New Directions in Sociological Thinking. Cambridge: Polity.

Stonewall (2008) 'A guide to conception through donor insemination'. Available at <www.stonewall.org.uk> (Accessed 14 August 2008)

Strathern, M. (1992) Reproducing the Future. Essays on Anthropology, Kinship and the New Reproductive Technologies. Manchester: Manchester University Press.

Strathern, M. (1995) 'Displacing knowledge. Technology and the consequences for kinship', pp. 346-363 in F. Ginsburg and R. Rapp (eds) Conceiving the New World Order. The Global Politics of Reproduction. Berkeley: University of California Press.

The BBC (2009) 'Lesbian given equal birth rights', 31 August. Available at <http://news.bbc.co.uk/1/hi/uk/8225158.stm> (Accessed 31 August 2009)

Weston, K. (1991) Families We Choose. Lesbians, Gays, Kinship. New York: Columbia University Press.

X v Y (2002) S.L.T (Sh Ct) 161, accessed via Westlaw UK

\footnotetext{
${ }^{1}$ This is illustrated in a Scottish court case, X v Y, (2002) S.L.T (Sh Ct) 161. A lesbian couple conceived using the sperm of a friend who believed that he would have contact with the child. After birth, the mothers reduced his visiting hours. When he took them to court the judge concluded that the donor did have a 'family relationship' with the child and should have parental rights but also that the non-birth mother did not have a 'family relationship' with the child. Consequently, she was exempted from such rights (see also Wallbank 2004).

${ }^{2}$ Almack (2008) has previously utilised the concept of 'display work' in the context of lesbian mother families and families of origin.

${ }^{3}$ The following five sites were selected for advertisement: 'Rainbownetwork' (www.rainbownetwork.com, now www.gaydarnation.com); 'Stonewall (www.stonewall.orgo.uk); 'LGBT parents' (www.lgbtparents.proboards74.com); 'Gingerbeer' (www.gingerbeer.co.uk); and 'Lesbian Insemination Support (http://groups.msn.com/LesbianInseminationSupport).

${ }^{4}$ It should be noted that this categorisation represents a snap shot of couples' routes to conception based on the actively pursued route at the time of the interview, or at the time of successful pregnancy. It should be noted, however, that many couples changed routes throughout their conception journey.
} 


\footnotetext{
${ }^{5}$ This is for example illustrated in the media coverage of the implementation of the new 2008 Act regulation that both lesbian partners can now be named on the birth certificate. BBC reports that ' $\mathrm{Dr}$ Peter Saunders, of the Christian Medical Fellowship, criticised the move, telling the Daily Mail that the change would "create a legal fiction around the parentage of the children"'(BBC News 2009). The BBC further reported that "he was supported by Labour MP Geraldine Smith, who said: "To have a birth certificate with two mothers and no father is just madness."'
} 